\title{
TRADUÇÃO DE AD FAMILIARES 5, 12I, DE MARCO TÚLIO CÍCERO
}

Adriano Scatolin*

\author{
M. Tulli Ciceronis \\ Ad Familiares V, 12 \\ Scr. Cumis (?) c. prid. Id. Apr. an. 55 \\ M. CICERO S. D. L. LUCCEIO Q. F.
}

1. Coram me tecum eadem haec agere saepe conantem deterruit pudor quidam paene subrusticus quae nunc expromam absens audacius; epistula enim non erubescit.

Ardeo cupiditate incredibili neque, ut ego arbitror, reprehendenda nomen ut nostrum scriptis illustretur et celebretur tuis. quod etsi mihi saepe ostendis te esse facturum, tamen ignoscas velim huic festinationi meae. genus enim scriptorum tuorum, etsi erat semper a me vehementer exspectatum, tamen vicit opinionem meam meque ita vel cepit vel incendit ut cuperem quam celerrime res nostras monumentis commendari tuis. neque enim me solum commemoratio posteritatis ac spes quaedam immortalitatis rapit sed etiam illa cupiditas ut vel auctoritate testimoni tui vel indicio benevolentiae vel suavitate ingeni vivi perfruamur.

\footnotetext{
${ }^{*}$ FFLCH - USP
} 
2. Neque tamen haec cum scribebam eram nescius quantis oneribus premerere susceptarum rerum et iam institutarum. sed quia videbam Italici belli et civilis historiam iam a te paene esse perfectam, dixeras autem mihi te reliquas res ordiri, deesse mihi nolui quin te admonerem ut cogitares coniunctene malles cum reliquis rebus nostra contexere an, ut multi Graeci fecerunt, Callisthenes Phocicum bellum, Timaeus Pyrrhi, Polybius Numantinum, qui omnes a perpetuis suis historiis ea quae dixi bella separaverunt, tu quoque item civilem coniurationem ab hostilibus externisque bellis seiungeres. equidem ad nostram laudem non multum video interesse, sed ad properationem meam quiddam interest non te exspectare dum ad locum venias ac statim causam illam totam et tempus arripere; et simul, si uno in argumento unaque in persona mens tua tota versabitur, cerno iam animo quanto omnia uberiora atque ornatiora futura sint.

Neque tamen ignoro quam impudenter faciam qui primum tibi tantum oneris imponam (potest enim mihi denegare occupatio tua), deinde etiam ut ornes me postulem. quid si illa tibi non tanto opere videntur ornanda? 3. sed tamen, qui semel verecundiae finis transierit, eum bene et naviter oportet esse impudentem. itaque te plane etiam atque etiam rogo ut et ornes ea vehementius etiam quam fortasse sentis et in eo leges historiae neglegas gratiamque illam de qua suavissime quodam in prohoemio scripsisti, a qua te flecti non magis potuisse demonstras quam Herculem Xenophontium illum a Voluptate, eam, si me tibi vehementius commendabit, ne aspernere amorique nostro plusculum etiam quam concedet veritas largiare.

Quod si te adducemus ut hoc suscipias, erit, ut mihi persuadeo, materies digna facultate et copia tua. 4. a principio enim coniurationis usque ad reditum nostrum videtur mihi modicum quoddam corpus confici posse, in quo et illa poteris uti civilium commutationum scientia vel in explicandis causis rerum novarum vel in remediis incommodorum, cum et reprehendes ea quae vituperanda duces et quae placebunt 
exponendis rationibus comprobabis et, si liberius, ut consuesti, agendum putabis, multorum in nos perfidiam, insidias, proditionem notabis. multam etiam casus nostri varietatem tibi in scribendo suppeditabunt plenam cuiusdam voluptatis, quae vehementer animos hominum in legendo te scriptore tenere possit. nihil est enim aptius ad delectationem lectoris quam temporum varietates fortunaeque vicissitudines. Quae etsi nobis optabiles in experiendo non fuerunt, in legendo tamen erunt iucundae habet enim praeteriti doloris secura recordatio delectationem; 5. ceteris vero nulla perfunctis propria molestia, casus autem alienos sine ullo dolore intuentibus, etiam ipsa misericordia est iucunda. quem enim nostrum ille moriens apud Mantineam E paminondas non cum quadam miseratione delectat? qui tum denique sibi evelli iubet spiculum postea quam ei percontanti dictum est clipeum esse salvum, ut etiam in vulneris dolore aequo animo cum laude moreretur. cuius studium in legendo non erectum Themistocli fuga †redituque $\dagger$ retinetur? E tenim ordo ipse annalium mediocriter nos retinet quasi enumeratione fastorum; at viri saepe excellentis ancipites variique casus habent admirationem, exspectationem, laetitiam, molestiam, spem, timorem; si vero exitu notabili concluduntur, expletur animus iucundissima lectionis voluptate.

6. Quo mihi acciderit optatius si in hac sententia fueris, ut a continentibus tuis scriptis, in quibus perpetuam rerum gestarum historiam complecteris, secernas hanc quasi fabulam rerum eventorumque nostrorum. habet enim varios actus multasque $<$ mut $>$ ationes et consiliorum et temporum. ac non vereor ne adsentatiuncula quadam aucupari tuam gratiam videar cum hoc demonstrem, me a te potissimum ornari celebrarique velle. neque enim tu is es qui quid sis nescias et qui non eos magis qui te non admirentur invidos quam eos qui laudent adsentatores arbitrere; neque autem ego sum ita demens ut me sempiternae gloriae per eum commendari velim qui non ipse quoque in me commendando propriam ingeni gloriam consequatur. 7. neque enim 
Alexander ille gratiae causa ab Apelle potissimum pingi et a Lysippo fingi volebat, sed quod illorum artem cum ipsis tum etiam sibi gloriae fore putabat atque illi artifices corporis simulacra ignotis nota faciebant, quae vel si nulla sint, nihilo sint tamen obscuriores clari viri. nec minus est $S \mathrm{pa}<\mathrm{r}>$ tiates Agesilaus ille perhibendus, qui neque pictam neque fictam [tam] imaginem suam passus est esse, quam qui in eo genere laborarunt. unus enim Xenophontis libellus in eo rege laudando facile omnis imagines omnium statuasque superavit.

Atque hoc praestantius mihi fuerit et ad laetitiam animi et ad memoriae dignitatem si in tua scripta pervenero quam si in ceterorum quod non ingenium mihi solum suppeditatum fuerit tuum, sicut Timoleonti a Timaeo aut ab Herodoto Themistocli, sed etiam auctoritas clarissimi et spectatissimi viri et in rei publicae maximis gravissimisque causis cogniti atque in primis probati, ut mihi non solum praeconium, quod, cum in Sigeum venisset, Alexander ab Homero Achilli tributum esse dixit, sed etiam grave testimonium impertitum clari hominis magnique videatur. placet enim Hector ille mihi Naevianus, qui non tantum 'laudari' se laetatur sed addit etiam 'a laudato viro'.

8. Quod si a te non impetro, hoc est, si quae te res impedierit (neque enim fas esse arbitror quicquam me rogantem abs te non impetrare), cogar fortasse facere quod non nulli saepe reprehendunt: scribam ipse de me, multorum tamen exemplo et clarorum virorum. sed, quod te non fugit, haec sunt in hoc genere vitia: et verecundius ipsi de sese scribant necesse est si quid est laudandum et praetereant si quid reprehendendum est. accedit etiam ut minor sit fides, minor

auctoritas, multi denique reprehendant et dicant verecundiores esse praecones ludorum gymnicorum, qui, cum ceteris coronas imposuerint victoribus eorumque nomina magna voce pronuntiarint, cum ipsi ante ludorum missionem corona donentur, alium praeconem adhibeant, ne sua voce se ipsi victores esse praedicent. 9. haec nos vitare cupimus et, si recipis causam nostram, vitabimus idque ut facias rogamus. 
Ac ne forte mirere cur, cum mihi saepe ostenderis te accuratissime nostrorum temporum consilia atque eventus litteris mandaturum, a te id nunc tanto opere et tam multis verbis petamus, illa nos cupiditas incendit de qua initio scripsi, festinationis, quod alacres animo sumus ut et ceteri viventibus nobis ex libris tuis nos cognoscant et nosmet ipsi vivi gloriola nostra perfruamur.

10. His de rebus quid acturus sis, si tibi non est molestum, rescribas mihi velim. si enim suscipis causam, conficiam commentarios rerum omnium; sin autem differs me in tempus aliud, coram tecum loquar. tu interea non cessabis et ea quae habes instituta perpolies nosque diliges.

\section{TRADUÇÃO}

\section{Marco Túlio Cícero}

Aos Amigos V, $12^{\mathrm{iii} 1}$

Cumas (?), c. 12 de abril de 55 a.C.

Marco Cícero saúda Lúcio Luceio, filho de Quinto

1. E mbora o tentasse muitas vezes, um pudor um tanto tímido impediu-me de tratar em pessoa, contigo, exatamente deste assunto que agora, à distância, revelarei com bastante audácia - é que uma carta não cora.

Ardo de um desejo incrível e, na minha opinião, nada censurável, de que meu nome ganhe brilho e celebridade por

1 Tradução feita a partir do texto latino estabelecido por D. R. S hackleton B ailey e publicado em Cicero, Select Letters, edited by D. R. Shackleton B ailey. C ambridge, Cambridge University Press, 2000, pp. 41-45. Agradecemos a nosso colega, Prof. Dr. J oão Angelo Oliva Neto, pela cuidadosa revisão do texto e pelas diversas soluções de tradução sugeridas. 
meio de teus escritos. E mbora muitas vezes prometas que o farás, gostaria que perdoasses esta minha impaciência: é que, embora eu tenha sempre aguardado ansiosamente conhecer a natureza de teus escritos, ela superou minha expectativa, me tomou e incendiou de tal forma, que desejei que os meus feitos fossem o mais rapidamente possível confiados a teus relatos históricos. De fato, não me arrebata apenas a idéia da recordação por parte da posteridade e certa esperança de imortalidade, mas também o desejo de desfrutar, ainda vivo, seja da autoridade de teu testemunho, seja da marca de tua benevolência, seja do encanto de teu engenho.

2. No entanto, ao escrever estas palavras, não ignoro o quanto te preme o enorme fardo dos trabalhos que assumiste e já iniciaste. Porém, por perceber que já quase completaste a História da Guerra Itálica e a História da Guerra Civil (tu me disseste que já havias começado os demais trabalhos), não quis deixar de te advertir que reflitas se preferes reunir minhas façanhas juntamente com as demais ou, como muitos gregos fizeram - Calístenes, no caso da Guerra da Fócida; Timeu, no da Guerra de Pirro; Polibio, no da Guerra da Numância, que separaram, todos, de suas histórias universais as guerras a que fiz menção - se preferes também tu, igualmente, separar a conjuração civil das guerras contra inimigos externos. De minha parte, percebo que não faz muita diferença para o meu louvor, mas faz, sim, alguma diferença para a minha pressa, que não esperes até chegar a esse passo para arrebatares de imediato toda essa oportunidade e ocasião; e se, ao mesmo tempo, tua mente se ocupar de um único argumento e de uma única personagem, sou já capaz de antever o quanto tudo ficará mais rico e ornado.

$\mathrm{E}$, contudo, não ignoro a impudência com que ajo ao te impor, em primeiro lugar, tamanho fardo (na verdade, teus encargos podem me recusar), em seguida, ao exigir também que me ornes. E se esses fatos não te parecerem dignos de tão grande esforço para orná-los? 3. No entanto, quem ultrapassou uma vez os limites da vergonha deve ser impudente da 
cabeça aos pés. S endo assim, peço- te aberta e reiteradamente que não apenas ornes com maior ardor do que talvez seja tua opinião, mas que também, ao fazê-lo, negligencies as leis da História e, quanto àquela parcialidade - acerca da qual escreveste com extremo encanto em certo proêmio, explicando que não pudeste ser dobrado por ela mais do que o famoso Hércules de Xenofonte pela Volúpia - peço que não a desdenhes, caso me recomendes com muito afinco, e presenteies meu afeto um pouquinho mais do que a verdade permitir.

4. Se te persuadir a tal empresa, a matéria será, em meu entender, digna de tua capacidade e de teus recursos. D e fato, parece- me que é possível estabelecer um corpus módico a partir do princípio da conjuração até o meu retorno, no qual poderás também fazer uso de teu conhecimento das mudanças civis, quer mostrando as causas das revoluções, quer mostrando os remédios para os reveses, quando não apenas repreenderás o que considerares digno de vitupério, mas também comprovarás, expondo argumentos, o que te aprouver, e, se julgares que deves tratar a matéria com mais franqueza, como é teu costume, apontarás a perfídia, as ciladas, a traição de muitos contra mim. É que, ao escreveres, nossas desventuras te fornecerão uma variedade repleta de prazer tal, que será capaz de reter fortemente a atenção dos leitores, contanto que sejas tu o escritor. De fato, nada é mais adequado ao deleite do leitor do que a mudança das circunstâncias e as vicissitudes da fortuna: e elas, se não foram desejáveis quando as experimentei, serão, porém, prazerosas na leitura. É que a recordação em segurança de uma dor passada provoca prazer; 5. mas para os outros, que não passaram por nenhum pesar pessoal e contemplam as desventuras alheias sem nenhuma dor, até a misericórdia é, por si mesma, prazerosa. Pois a qual de nós o famoso E paminondas, morrendo em Mantineia, não provoca uma mistura de prazer e comiseração, quando ordena que se arranque a flecha de seu corpo só depois que, em resposta ao que perguntara, disseram que seu escudo estava salvo, de 
modo que, mesmo em meio à dor da ferida, pudesse morrer em paz e com honra? A que leitor a fuga e o retorno de Temístocles não retêm a atenção? E, de fato, a própria ordem dos anais nos retém medianamente em virtude da lista, por assim dizer, dos fastos; mas não raro as desventuras incertas e variadas de um homem excelente provocam admiração, expectativa, alegria, pesar, esperança, temor; se se concluem com um fim notável, enche-se a mente de um prazer de ler extremamente agradável.

6. Por isso, eu preferiria que concordasses em separar de teus escritos contínuos, em que contemplas a história universal, esta fábula, por assim dizer, de minhas façanhas e sucessos: é que ela contém ações variadas e muitas mudanças tanto de desígnios como de circunstâncias. E não receio parecer estar à cata de teu favor com uma bajulação barata ao demonstrar que é sobretudo por ti que desejo ser ornado e celebrado: nem tu és do tipo que desconheces o que és, julgando invejosos os que não te admiram e bajuladores os que te elogiam; nem eu sou tão demente a ponto de querer confiar-me à glória eterna por meio de alguém que por si mesmo não consiga também uma glória adequada a seu engenho. $\mathbf{7}$. $\mathrm{E}$, de fato, não era por favorecimento que o famoso Alexandre queria ser pintado sobretudo por Apeles e esculpido por Lisipo, mas porque julgava que a sua arte seria motivo de glória tanto para eles quanto para o próprio Alexandre. E aqueles artífices tornavam os simulacros de corpo deles conhecidos a quem não os conhecia, e, se estes simulacros não existissem, os homens ilustres não seriam nem um pouco mais obscuros. E Agesilau, o famoso espartano que não permitiu que se pintasse ou esculpisse sua imagem, não é menos digno de narrar do que aqueles que trabalharam no gênero historiográfico em questão, pois o pequeno livro de Xenofonte, sozinho, ao louvar esse rei, superou facilmente a todas as esculturas e todas as estátuas.

E para mim - quer para minha alegria, quer para a dignidade de minha memória - será mais vantajoso comparecer 
nos teus escritos do que nos dos outros, porque não se me fornecerá apenas teu engenho, como ocorreu a Timoleonte no caso de Timeu e, no de Heródoto, a Temístocles, senão também a autoridade de um homem muitíssimo ilustre e distinto, reconhecido e mais que todos aprovado nas causas mais importantes e sérias da República, de modo que parecerá terme sido conferido não apenas o panegírico que, ao chegar ao Sigeu, Alexandre disse ter Homero atribuído a Aquiles, mas também o testemunho grave de um ilustre e grande homem. De fato, agrada-me o célebre Heitor de Névio, que não se alegra apenas por "ser louvado", mas também, acrescenta, "por um homem louvado".

8. S e não o obtiver de ti, ou seja, se algo te impedir (pois não considero sacrilégio não obter algo que te peça), serei talvez obrigado a fazer o que não raro alguns criticam: escreverei eu mesmo a meu respeito, seguindo, contudo, o exemplo de homens numerosos e ilustres. Porém, como não te escapa, há os seguintes defeitos nesse gênero: é forçoso que escrevam a respeito de si mesmos com muito pudor, se houver algum motivo de elogio, e que omitam, se houver algo censurável. Soma-se ainda o fato de que é menor a credibilidade, menor a autoridade, e que muitos, enfim, criticam essa prática, afirmando que têm maior pudor os arautos dos jogos gímnicos, pois coroam os demais vencedores e anunciam os nomes deles em voz alta, mas quando eles próprios são premiados com a coroa, convidam outro arauto antes do término dos jogos a fim de que não anunciem sua vitória com a própria voz 9. Eu gostaria de evitar isso e, se aceitares minha causa, hei de evitar, e peço que aceites.

E para que não te cause admiração que, embora muitas vezes proclames que darás às letras as decisões e os acontecimentos de meu consulado com o maior zelo, eu o peça agora a ti com tamanha insistência e tantas palavras, incendeia-me aquele desejo de pressa sobre o qual escrevi no início, porque anseio que os outros me conheçam pelos teus livros enquanto estou vivo e que, ainda vivo, eu desfrute de minha pequenina glória. 
10. Gostaria, se não te fosse incômodo, que me respondesses o que farás a respeito. Se assumires a causa, comporei apontamentos sobre todos os fatos; mas, se me adiares para outra ocasião, falarei pessoalmente contigo. Tu, entrementes, não ficarás ocioso: vais dar lustro ao que iniciaste e conceder-me tua estima. 